\title{
La crisis de nuestro tiempo. Análisis del concepto de Historia en José Ortega y Gasset.
}

The crisis of our time. Analysis of the concept of History in José Ortega y Gasset.

\author{
Israel Alejandro Romero Ramírez \\ Departamento de Humanidades, Artes y Culturas Extranjeras. Universidad de Guadalajara (MÉXICO) \\ CE: israel.alejandro.rr@gmail.com
}

DOI: $10.32870 /$ sincronia.axxiv.n77.3a20

Esta obra está bajo una Licencia Creative Commons Atribución-NoComercial 4.0 Internacional

$B Y \cdot N C$

Recibido: 22/03/2019

Revisado: $11 / 09 / 2019$

Aprobado: 30/10/2019

\section{RESUMEN}

Este ensayo tiene la intención de recorrer el concepto de Historia en tres libros del filósofo español: La rebelión de las masas, Historia como sistema y El centenario de Hegel. El recorrido que se piensa llevar a cabo no pretende agotar una definición tan rica en significados en la obra de Ortega y Gasset. Emprender una campaña de esa magnitud hubiera implicado un trabajo muy extenso. Lo que me interesa en realidad es abordar cuatro aspectos específicos que han sido de mi interés desde hace tiempo: 1) La injusticia entorno a una lectura política de su obra, haciendo en la mayoría de las veces un oscurecimiento de su sentido filosófico. 2) Revisaremos algunos aspectos de la guerra civil española así como el llamado silencio de Ortega, también analizaremos la tercera visita que llevó a cabo el filósofo español a la Argentina y el clima adverso al que se deberá enfrentar su persona y su pensamiento. 3) La urgencia de pensar una filosofía que rompa con la tradición historicista de Hegel para interpretar el presente; en este último punto es donde analizaré su concepto de Historia.4) Analizar la irrupción de las ideologías en su época y el impacto que tuvieron en las masas (hombre medio). 
Palabras clave: Ideología. Historia. Circunstancia. Liberalismo.

\section{ABSTRACT}

This essay intends to explore the concept of History in three books of the spanish philosopher: The rebellion of the masses, History as a system and Hegel's centenary. The route that is thought to carry out does not pretend to exhaust a definition so rich in meaning in the work of Ortega y Gasset. Undertaking a campaign of this magnitude would have involved extensive work. What really interests me is to address four specific aspects that have been of my interest for some time: 1) The injustice surrounding a political reading of his work, often making a mutilation of his philosophical sense. 2) We will review some aspects of the spanish civil war as well as the so-called silence of Ortega, we will also analyze the third visit that the Spanish philosopher made to Argentina and the adverse climate to which his person and his thought will have to face. 3) The urgency of thinking a philosophy that breaks with the historicist tradition of Hegel to interpret the present; in this last point is where I will analyze his concept of History.4) Analyze the irruption of ideologies in his time and the impact they had on the masses (middle man).

Keywords: Ideology. History. Circumstance. Liberalism.

\section{Por una lectura no ideológica de José Ortega y Gasset.}

La filósofa, Hannah Arendt, en su libro La condición humana (2017), nos muestra la separación entre lo que llama vita activa y la vita contemplativa. La separación consiste en la bifurcación de dos modos de vida: la vida política y la vida filosófica; ambas quedan, según Arendt, desarticuladas desde Platón. La acción remite a la vida pública y concreta del ser humano, mientras que la vida contemplativa es la vida teorética en la cual es importante el aislamiento y la distancia con respecto a los asuntos humanos: 
La superioridad de la contemplación sobre la actividad reside en la convicción de que ningún trabajo del hombre puede igualar en belleza y verdad al kosmos físico, que gira inmutable y eternamente sin ninguna interferencia del exterior, del hombre o dios. (Arendt, 2017, p. 28).

Es por eso que los filósofos acuden a la serenidad, la soledad, el pensamiento abstracto; no obstante éstos se han dado a la tarea de pensar la política, pero siempre desde un aspecto reflexivo y de análisis conceptual. Rousseau, por ejemplo, cuando habló del estado de naturaleza, no es porque creyera que ese estado hubiera existido, sino que era necesario presuponerlo para distinguir entre un estado monárquico y la república. La visión de Rousseau está dentro de la bifurcación que nos muestra Arendt (vita contemplativa); pero debemos decir que José Ortega y Gasset no entraría dentro del esquema que la filósofa alemana nos propone.

José Ortega y Gasset decidió que su obra filosófica estuviera destinada a periódicos y ensayos. Su padre José Ortega Munilla dedicó su vida al periodismo, y será ese rastro imborrable el que marque la vida de su hijo. Hay que decir que el periodismo es un oficio que tiene como finalidad establecer un vínculo informativo entre el periodista y el pueblo en asuntos esenciales de la vida política y pública. Es por eso que el destino de Ortega y Gasset no podrá ser otro que el diálogo con el pueblo español: "Hoy, en cambio, el hombre medio tiene las ideas más taxativas sobre cuanto acontece y debe acontecer en el universo. Por eso ha perdido el uso de la audición" (Ortega, 2014a, p. 321).

El filósofo español pide ser escuchado, quiere hacerse llegar a la gente, ya que un diagnóstico, si el enfermo lo ignora, pondría en riesgo su vida. Pero, ¿cómo hacer llegar el mensaje? Es precisamente en ese encuentro del pueblo con el filósofo en donde se ponen en juego muchas cosas por ambas partes. Para quien escuche la voz del filósofo la pregunta que se hace es: ¿qué hacer con eso que me dice? Con respecto al filósofo, corre el riesgo de ser incomprendido, dolor que no es solamente personal -si se quiere ver de esa manera-, sino que su modo de vida quedaría expuesto y a su vez cuestionado. Zaratustra, en el pensamiento de Nietzsche, es el mejor ejemplo que tenemos: "iMira! Estoy harto de mi sabiduría como la abeja que ha recolectado demasiada miel, necesito de manos que se tiendan" (Nietzsche, 2014, p. 16). 
Ortega y Gasset fue el filósofo más universal que ha tenido España. Es cierto que se mantuvo, por varios años, como profesor de la Universidad de Madrid. Pasarán unos años todavía para que encuentre su auténtico camino, que no será el mundo académico. Hizo dos viajes fundamentales a Alemania. Durante tres años, entre 1905 y 1908, estuvo en la prestigiosa universidad de Marburgo, donde tuvo como maestros a Herman Cohen y Paul Natorp, ambos reconocidos representantes del neokantismo. Su trabajo al volver a España fue el de transmitir las filosofías y los autores de vanguardia; solo por mencionar a Oswald Spengler, Edmund Husserl, Georg Simmel; este último influyó en sus trabajos sociológicos. En el caso específico de Simmel, encontramos que su idea en cuanto a qué es el arte, nos permite tomar distancia de la relación inmediata que tenemos nosotros con los objetos; coincide su pensamiento con el concepto de Ortega del perspectivismo: el arte nos permite ver la realidad desde distintos ángulos, lo que nos hace poder concebir y reflexionar en distintas maneras lo que llamamos realidad. De la misma manera, cuando el filósofo se enfrenta a lo inmediato tiene que aprender a tomar distancia para poder valorar, sin dejar de lado su realidad circundante. Por consiguiente, la realidad solo puede ser tomada a partir de conceptos. La relación de cercanía entre nosotros y los objetos a lo mucho solo lograría tener una intuición o corazonada de algo; por otro lado, la distancia sin concepto es la deshumanización (indiferencia, apatía). Con el tiempo Ortega tomará distancia de sus antiguos maestros neokantianos, pues se opone al subjetivismo (interioridad).

Recordemos que en la cita anterior, cuando Ortega hace hincapié en que la masa ha perdido el uso de la audición, el problema es que ya sea la cercanía o la distancia, si se hace de lado la relación dialéctica, ${ }^{1}$ nos lleva a entender el problema de su tiempo; me refiero a que las masas viven alejadas de sus circunstancias. En la gran biografía que escribe Jordi Gracia, José Ortega y Gasset, nos habla de lo que el filósofo español definió como selección inversa:

\footnotetext{
${ }^{1}$ Es importante que la palabra dialéctica no quede relacionada al significado hegeliano. El sistema hegeliano nos lleva a un determinismo de la historia, en la que el hombre es un espectador del devenir del espíritu absoluto. Para Ortega vivir es ser lanzado a una circunstancia, quiere decir que es una vida que crea su vida. El hombre no es un espectador, sino que se vuelve él mismo un protagonista. Como se puede ver, en su pensamiento, no se trata de la dialéctica en el sentido de Hegel.
} 
[...] existe también el daltonismo de los valores y, en España, puestos entre dos valores subvertimos su proporción verdadera. Hay un odio a lo mejor por ser mejor y una simpatía hacía lo abyecto. Esta es la perversión de los instintos valoradores. (Gracia, 2015, p. 196).

La fecha en la que elabora el concepto de "selección inversa" es aproximadamente el año de 1914. Esta fecha coincide perfectamente con la crisis de la Restauración en España. Primeramente tenemos la destitución de Unamuno del rectorado de la Universidad de Salamanca. Pensadores distinguidos como Eugenio d'Ors se van a pronunciar de manera enérgica contra lo sucedido a Unamuno. Ortega no será la excepción y hará un llamado también:

El día 7 vuelve Ortega a dar la señal de alarma a las huestes y en carta al director del periódico más afín, El País, exige que los intelectuales aprovechen esta ocasión esplendida para dar un fuerte ejemplo de solidaridad, para ensayar nuestras energías, que mañana hemos de unir a las de los productores y los obreros en una formidable rebelión de los más puros, hondos y vejados instintos españoles. (Gracia, 2015, p. 193).

A pesar de las discrepancias que pudo tener Ortega en su momento con Unamuno, nunca dejó de reconocer en aquel incidente de la rectoría una profunda indignación. ${ }^{2}$ Ahora bien, la crisis de la Restauración, remite a dos planos organizados por un mismo eje: La Primera Guerra Mundial. Por un lado España fue neutral en el conflicto, hablando diplomáticamente, pero Ortega piensa que la sociedad española vive con cierta lejanía lo que ocurre en Europa, es acaso un síntoma de lo que el filósofo veía en lo referente a España, una nación distanciada de Europa ${ }^{3}$. El otro punto es que España se enfrentará a una crisis económica, efecto de la guerra continental que se libra en gran

\footnotetext{
${ }^{2}$ Se sabe bien que cuando un filósofo escribe mantiene un diálogo con otro pensador. José Ortega y Gasset mantuvo un diálogo fuerte e intenso con varios filósofos, en sus escritos, y en distintas etapas, y uno de ellos fue Unamuno. Aunque su diálogo tuvo un fin cuando Ortega entendió que estaba muy lejos de Unamuno. Hubo un momento en el que los temas de uno ya no importaban al otro. Ni Dios, ni lo místico, ni lo trascendental, ni San Juan de la Cruz, ni Santa Teresa fueron temas de importancia para Ortega. Quizás el único tema que tuvieron en común, por un tiempo, no pudo ser otro que su modo de filosofar sobre España.

${ }^{3}$ Tema relevante en su libro La rebelión de las masas.
} 
parte de Europa ${ }^{4}$. Dicha crisis, que se origina de la guerra, recrudeció las distancias sociales, las cuales se marcaron e hicieron que las masas tomaran posiciones ideológicas que con el tiempo serán fundamentales para entender otros problemas que vendrán. La crisis de 1916 será parte del hilo conductor de dos años atrás. Hay que recordar que Santiago de Alba propuso una reforma fiscal la cual se vino abajo, los salarios reales se deterioraron más, y a eso le sumamos una clase obrera que sabe organizar huelgas. Ortega descubrió a través de estos sucesos el profundo atraso de España y el apuro que se vislumbraba hacia el futuro para hacer frente a los problemas estructurales del país (crisis económica y moral). Crisis de gobiernos liberales que no tardarán en ser sustituidas por dictaduras militares como la de Miguel Primo de Rivera.

La idea de distancia que hemos estado explicando constantemente, la cual aleja a las masas de su circunstancia, no puede llevar a estas mayorías a otro lado que a un debilitamiento de su fuerza vital. Un rasgo que se deriva de esta distancia con respecto a la circunstancia es la pasividad, la ausencia de reflexión y conexión: "Su vida pierde, inexorablemente, autenticidad y se convierte en pura representación o ficción de otra vida" (Ortega, 2014a, p. 341). Esta distancia del pueblo y su circunstancia se dirige contra el filósofo español, no solamente a su persona, sino peor aún: con respecto a sus ideas. Ortega y Gasset hablaba desde la distancia. Aclaremos que no era una distancia que él zanjara, sino una distancia que los otros crearon con respecto a sus ideas. Su infortunio no se hace esperar: Ortega y Gasset fue leído políticamente y no filosóficamente; en eso consiste su tragedia. Por eso mismo, Sócrates no decidió hablarles a las mayorías, sino que resolvió por el camino de la mayéutica; el hablar uno por uno. Aunque esta decisión que tomó el filósofo griego no hizo que le fuera mejor que a Ortega. El tema de la relación del filósofo con las mayorías es un tema profundo y poco analizado. ${ }^{5}$ Menciono la necesidad de profundizar, no porque no se haya escrito sobre el asunto, sino que cuando los filósofos han intentado poner en práctica dicha

\footnotetext{
${ }^{4}$ La neutralidad parece que le costó a España unos cuantos barcos hundidos en represalia por parte de los alemanes.

${ }^{5} \mathrm{El}$ hecho de que el filósofo español aparezca en algunas historias de la filosofía no quiere decir que su pensamiento no esté oscurecido por el entorno político de su época. Podemos constatar que en vida así lo sintió el propio Ortega en sus auto-exilios y en otros pasajes que cuenta de su vida. Otro aspecto doloroso fue el prestigio de la filosofía de Heidegger y las comparaciones que se hacían de ambas obras.
} 
relación, los resultados han sido desde la indiferencia que muestran a sus ideas hasta cuando su pensamiento se convierte en una moda. Esto último hace que su filosofía se vuelva en poco tiempo efímera, y finalmente, pase al olvido total. ${ }^{6}$

Hemos llegado a un punto nodal de nuestra discusión. Debemos insistir que el filósofo español fue leído en su época no siempre desde un plano filosófico, sino que fue leído políticamente por los republicanos y los nacionalistas. Ortega y Gasset vivió en un tiempo en el que había una crisis de valores (1936), no solamente al interior de España, sino que el filósofo la vislumbraba en toda Europa. La crisis tomará su mayor plenitud con la Guerra Civil Española. Esta guerra no deberíamos verla como un problema interno sino que debemos leer los acontecimientos ocurridos como el preámbulo de la Segunda Guerra Mundial. La intervención ecuménica de algunas personas en el conflicto nos hace ver que los voluntarios no iban a pelear por los españoles, sino que iban a pelear por ideologías: liberales, anarquistas, fascistas, comunistas. La guerra duró 3 años -1936 a 1939- y mostró la crueldad, pues para muchos historiadores fue la primera guerra moderna en la que se usaron aviones, tanques y armas de distintos calibres. Las ideologías se concentraron en dos frentes: nacionalistas y republicanos. Era obvio que esta guerra fue financiada desde el exterior por distintas potencias, pues la España de ese momento sufría de sectores de la población incluso analfabetas, no contaba todavía con infraestructura que comunicara a todas las regiones y ciudades, había pocos territorios que contaban con industria, y se podría decir que era, en gran medida, una economía que se sostenía de la agricultura. Culturalmente, mucha gente conservaba las tradiciones cristianas, y las ideas republicanas mostraron cambios que las hacían ver radicales desde cierto sector conservador: quema de iglesias, quitar la educación religiosa, quitar las propiedades al clero. Los últimos dos puntos, en una sociedad más avanzada, hubieran sido aceptados, pero la verdad es que tales cambios fueron recibidos de muy mala manera por los sectores conservadores. Hay que decir que cuando se piensa en el republicanismo de esa época, en

\footnotetext{
${ }^{6}$ Pienso en la filosofía de Sartre, quien generó la figura del intelectual que se comprometía con los asuntos de los obreros, los estudiantes, los oprimidos por el imperialismo (Argelia), etc. Sin embargo, la generación de pensadores que le siguieron fueron reaccionarios a su pensamiento hasta que fue prácticamente olvidado.
} 
realidad no tenía un significado único. La verdad es que bajo esa categoría había un crisol de ideologías que se movían desde la radicalidad a la moderación?:

El frente popular no reacciona como un bloque unido. Ante la eventualidad de la guerra, muestra su diversidad. Es una verdadera hidra revolucionaria-escribe Salvador de Maradiaga - con una cabeza sindicalista, otra anarquista, dos comunistas y tres socialistas, mordiéndose la una a la otra. (Eslava, 2016, p. 62).

Del lado de los nacionalistas aparece un militar que con el tiempo va a encabezar una dictadura religiosa; nos referimos a Francisco Franco. A pesar de que tenía una simpatía muy grande por Benito Mussolini y Adolf Hitler, para muchos historiadores, nunca logró construir un aparato ideológico, sino que creó tal y como se debe definir una dictadura religiosa.

Muy pronto los nacionalistas se movilizaron en pedir ayuda a Italia y Alemania, ya que ellos no tenían más que las tres cuartas partes del ejército y algunas ciudades como Galicia, Castilla Vieja, Andalucía occidental, Cáceres, Mallorca e Ibiza. Del bando de los republicanos tienen Cataluña, Madrid, Castilla la Nueva, Cáceres oriental, Badajoz, Málaga y Andalucía oriental. Hay datos fundamentales que tienen que ver con los recursos que ambas partes contaban y que serán determinantes en el curso de la guerra. La República no tenía muchos recursos para alimentar a la población, contaba tan solo con un tercio del trigo nacional, con una quinta parte de las vacas y con un décimo de ovejas (Eslava, 2016). Los republicanos cuentan con la mayoría del armamento y de soldados, se sabe que de los trescientos aviones, doscientos siete pertenecían al gobierno legítimo. La fuerza marítima se mantendrá con el gobierno.

Un momento crucial en el conflicto español es cuando el militar Francisco Franco pedirá ayuda a Hitler, sabemos que primero se dirigió de manera diplomática a Relaciones Exteriores con el ministro Neurath. Alemania se negó en un principio a colaborar con un gobierno golpista. Esta

${ }^{7}$ Cuando dimitió de su cargo Manuel Azaña, de la presidencia de la Segunda República para que Franco tomara el poder absoluto, los únicos que se negaron a deponer las armas fueron los comunistas que lucharon en varios frentes hasta el final. 
declaración, por parte del ministro, ahora sabemos que fue en su momento desconocida por Hitler. Hay que recordar que él, en ese momento, no conocía a Franco.

Rememorando una de las proezas más grandes de la historia el piloto, Alfred Henke Van Bernhardt y un oficial de aviación, el capitán Francisco Arranz viajarán a Berlín. La pregunta obligada es qué hará que Hitler ayude a España. Goering le informará a Hitler que pueden obtener hierro y wolframio. Pero el punto fundamental será el saber que los comunistas están detrás del gobierno republicano. Sabemos que el odio que tenía Hitler al comunismo no tenía límite:

Si acaso, procura que la intervención alemana en ese conflicto para lo más inadvertida posible. Se crea una compañía comercial HIMSA (Hispano-Marroquí) para encauzar las ayudas bajo cobertura civil. El ministro de Propaganda Goebbels cursa instrucciones a la prensa: a partir de hoy los españoles rebelados contra el Gobierno no se denominaran rebeldes sino nacionalistas. (Eslava, 2016, p. 52).

Un claro ejemplo de la manipulación de información a través de un aparato ideológico. Ahora bien, el contexto de Ortega no puede ser peor, entiende a la perfección que ambas partes han caído en la barbarie: nacionalistas y republicanos. Un pueblo enfrentado entre sí y, por otro lado, un intervencionismo internacional nunca antes visto.

Hacia el final de la Guerra Civil, para ser exactos en el año de 1939, vuelve Ortega a visitar Argentina. ${ }^{8}$ Para la visita ya había publicado La rebelión de las masas, uno de los libros que revisaremos a continuación. Pero esta visita no fue lo que en la primera se dio. El silencio de Ortega y Gasset con respecto a ambas partes, nacionalismo y republicanismo, le cobrará factura, no se le otorgará ninguna cátedra y tendrá serias dificultades para su manutención:

O sea, que si una circunstancia se encuentra dominada básicamente por el factor ideológico político, por ejemplo, muy bien puede suceder que sea este ámbito el decisivo también en lo que se refiere a la recepción o rechazo de una influencia cultural o estrictamente filosófica. (Medin, 1994, p. 123).

\footnotetext{
${ }^{8}$ Ortega y Gasset había visitado la Argentina en 1916 con el recibimiento en su posición de filósofo.
} 
En Argentina había muchos exiliados españoles y como hemos mencionado, la guerra civil española al ser un conflicto ideológico polarizaba a todo el mundo. Sucesos también marcaron su estancia en la Argentina, como el que dos de sus hijos pelearon en las filas del franquismo, todo complicó la estancia del filósofo español. ${ }^{9}$ Victoria Ocampo, íntima amiga de Ortega y Gasset, recibió al filósofo con palabras muy emotivas, pero como lo muestra Medin, en una de sus cartas Ortega no piensa lo mismo que su amiga:

Victoria Ocampo: Ortega y Gasset no está aquí de visita, entre extraños. Está en su casa entre amigos.

Carta de Ortega y Gasset: Puedo decirte que desde febrero mi existencia no se parece absolutamente nada a lo que ha sido hasta entonces y que sin posible comparación atravieso la etapa más dura de mi vida [...] haz el favor de imaginar un momento en que vez de una te fallasen a la vez todas las dimensiones de la vida y con ello tendrías una idea de lo que a mí me pasa. (Medin, 1994, p. 124)

Es conocido que Ortega y Gasset siempre tuvo necesidad de reconocimiento, por múltiples motivos, que no le podemos recriminar. En muchas ocasiones interpretó incidentes de manera personal que lo llevaron a distanciarse de personas estimadas por él, entre ellas la propia Victoria Ocampo, Alfonso Reyes y Helene Weyl, entre otros. También tenemos que decir que en su momento será utilizado en esta última visita a la Argentina. Ortega entabló relación con grupos pro-franquistas y esto lo llevó a que fuera tachado de fascista. A pesar de que hay datos que prueban que rechazó en España hablar con José Antonio Primo de Rivera (creador de la falange y primogénito del dictador). La rebelión de las masas será leída por el grupo pro-franquista, claro que desde una lectura ideológica, hay algunos apartados en La rebelión de las masas en donde si uno no tiene un conocimiento de su filosofía nos llevaría a pensar en la legitimización de una clase dominante que no es justificable desde el texto. Las revistas Baluarte, Sol y luna y Nueva política hacen una lectura del filósofo español desde el tomismo cosa en sí aberrante (Etchecorpar, César Pico):

\footnotetext{
${ }^{9}$ Miguel y José fueron los nombres de los dos hijos de Ortega y Gasset que pelearon del lado del franquismo.
} 
La rebelión de las masas era una expresión de lo que sin demasiada falsificación de las ideas cabe llamar una visión política de derecha. [...] Y cuando Ortega escribe que no hay quien mande en el mundo, lo interpretamos como una invitación. (Medin, 1994, p. 126).

Será preocupante el nivel al que el pensamiento de Ortega será llevado. Podemos identificar ahora cómo es que se hace una lectura fascista y se exalta en otros momentos por el grupo un germanismo carente de reflexión. Su autoexilio de España y una decepcionante estancia en Argentina marcará profundamente su vida ${ }^{10}$. Parece que el pensamiento de Ortega y Gasset estaba destinado en ese momento a ser leído desde posturas ideológicas, siendo que fue un pensador que atisbó la ideología como uno de los males de nuestro tiempo.

\section{Dos ideas distintas de la historia: Hegel y Ortega y Gasset}

Hegel es quizás el filósofo que le ha dado a la historia un papel protagónico en la vida humana. A diferencia de la razón kantiana que es a histórica, pues no contempla el devenir y su manifestación en el tiempo histórico. Sabemos que Hegel nos hace ver el ser como un continuo que tiene como finalidad lo absoluto. El absoluto sería el fin de la historia, la totalidad, el momento en el que la humanidad llegue a su fin. Los demás momentos serían solamente una totalidad relativa que sería integrada siempre en el continuo: "Con ello, este inicio no es absoluto, sino que proviene del precedente movimiento de la conciencia" (Hegel, 2011, p. 216). Así podemos ver que la cualidad del ser es su indeterminación, si tiene esa cualidad el ser, entonces, no se puede diferenciar con respecto a nada. En la lógica de Parménides el ser se identifica con el pensar, lo que nos lleva a una lógica de oposiciones: el ser es y el no ser no es. Hegel nos muestra que Heráclito ante todo piensa el devenir: "Lo que el devenir contiene no es que nada siga siendo nada, sino que pase a su otro, al ser". -Cuando la metafísica posterior, la cristiana especialmente, rechazó la proposición: "que de

\footnotetext{
${ }^{10}$ Es importante recordar un incidente que dejará una huella profunda en el filósofo español. En la revista Sur se publica un artículo anónimo titulado "Capricho español", dicho artículo está cargado de ironía y de crítica a la postura franquista de Sol y luna. Ortega renunciara al comité de consulta. Este incidente marcaría la distancia entre Ortega y Gasset y Victoria Ocampo. Recuérdese que Victoria Ocampo fue una mujer muy importante en el mundo intelectual no solamente de Argentina.
} 
nada se hace nada". (Hegel, 2011, p. 227) La metafísica clásica piensa el ser en términos de una lógica de oposición, por ejemplo: ser, no ser; sujeto, objeto, adentro y afuera. La lógica de Hegel piensa la historia como una contradicción no simultanea, sino se piensa en un movimiento que oscila siempre del ser al no ser.

Así en la Fenomenología del espíritu, Hegel nos muestra que la historia se manifiesta en las acciones humanas. Es por eso que podemos hablar de hechos históricos. Pero esos hechos históricos solamente adquieren sentido en el devenir y cuando estos trascienden en una comprensión conceptual. No hay historia fuera del hombre y hay historia porque hay acciones y conceptos. La relación entre concepto y acción nos muestra el espíritu de una época, y a su vez ese concepto obedece al devenir de la conciencia histórica (el concepto y su relación con otros conceptos) $)^{11}$. Puesto que el hombre al tener conciencia, no solamente tiene conciencia de lo ahí presente, sino que tiene conciencia de un saber que se revela en su conjunto; este saber daría cuenta el filósofo y no el ideólogo, pues este último lo que lleva a cabo es una deformación del devenir ${ }^{12}$. La pregunta que podemos hacernos en este momento es con respecto al papel que juega Hegel dentro del pensamiento de Ortega y Gasset. Leamos la siguiente cita:

Pero los hechos de mi vida no terminan en ella, en su órbita individual, sino que actúan sobre la órbita de otras vidas como la mía, penetran en ella produciendo múltiples efectos. Y viceversa, lo que a otros les pasa - su vida - rezuma sobre la mía. (Ortega, 2014b, p. 261).

Ortega quiere hacernos ver que la palabra yo no puede contestarse desde la identidad. Piensa también que el concepto yo se ha convertido en algo habitual y por ende pierde su sentido. Ortega quiere que veamos que el sentido es el del peldaño histórico, como cuando uno sube y ve que más allá de una barda se encuentra un campo que no había sido visto antes. Ese campo no es ajeno a mí, la vida de los otros nunca me es ajena, ni de los que viven en mi presente, ni tampoco de aquellos

\footnotetext{
${ }^{11}$ La filosofía de Hegel nos lleva a una antropología filosófica.

${ }^{12}$ La filosofía misma corre el peligro de volverse ideología.
} 
que ya no viven en este presente. Es por eso que Ortega y Gasset nos recrea la imagen de un cuarto en donde alguien escucha cuchicheos y se pregunta: ¿Quién anda ahí? Nietzsche usa la palabra tras vestidores, lo que pasa sin darnos cuenta, eso que sucede tras vestidores son los sucesos históricos. Así que el problema es pensar si la Historia se puede mostrar de manera transparente y la respuesta será que no. Ortega disiente de Hegel y de Marx con respecto a la idea abstracta de una realidad objetiva. Para que sea transparente para otro tendría que mostrarse por fuerza una realidad objetiva de la cual se desprendan otras:

En esta prosperidad general en la que las fuerzas productivas de la sociedad burguesa se desarrollan con tanta abundancia cómo es posible en el marco de las relaciones burguesas, no cabe hablar de una verdadera revolución. Una revolución así solo es posible en los períodos en los que estos dos factores, las fuerzas productivas modernas y las formas burguesas de producción entran en contradicción. (Marx, 2014, P. 133).

Sabemos que la diferencia entre Marx y Hegel es que el primero piensa la Historia desde la Economía, el segundo lo hace desde la Filosofía:

Con respecto a Marx: “El hombre no actúa según sus ideas, sentimientos, etcétera, sino, al revés, las ideas, sentimientos de un hombre, son consecuencia de su situación social, esto es, económica". (Ortega, 2014b, p. 264).

La lógica hegeliana como el marxismo en su interpretación de la Historia se le muestra a Ortega como pensamientos sospechosos por hacer una interpretación abstracta de la realidad. Ortega propone pensar una historia de las diferencias y de los detalles (tomando en cuenta la psicología), podemos ver que tan cerca se encuentra el filósofo español del pensamiento de Dilthey.

Es importante ahora mencionar que Ortega y Gasset tendrá una separación con respecto al pensamiento kantiano: "Kant ha sido durante diez años, dice ahora, en mayo de 1924, mi casa y mi prisión, pero ya ha escapado a su influjo atmosférico" (Gracia, 2015, p. 367). Será a partir de Dilthey 
que supere el idealismo y el racionalismo. ${ }^{13}$ Podemos decir que para Ortega, Hegel padece del mismo problema, su pensamiento es analítico y busca comprenderlo todo, nada puede quedar por fuera del sistema. Su reflexión es abstracta y por lo mismo no puede entender la historia porque le hace falta entender la vida. La propuesta de Ortega es el de poner la cultura al servicio de la vida:

Llega, pues, a lo histórico autoritariamente, no con ánimo de aprender de la historia, sino, al revés, resuelto a averiguar si la historia, si la evolución humana se ha portado bien, quiero decir, si ha cumplido su deber de ajustarse a la verdad que la filosofía ha descubierto. Este método autoritario es lo que Hegel llama Filosofía de la historia. (Ortega, 2014b, p. 267).

Su determinismo histórico lo podemos identificar en el concepto de propósito. Al hablar de un propósito queda superado todo aquello que sea singular, quiero decir que mis conductas pertenecen a un conjunto que sigue un movimiento teleológico. Me determina el tiempo y el lugar en el que me encuentro. En Hegel yo no soy otra cosa más que un alfiler enredado en una red compleja de hilos. En su sistema el espíritu siempre se encarna en un tiempo histórico, en una cultura, en un Estado, en un héroe. Por lo tanto, el hombre individual en el pensamiento de Hegel se convierte en alguien que sólo le queda contemplar la historia.

\section{El concepto de Historia en Ortega y Gasset}

El pensamiento de Ortega y Gasset no aspira a ninguna trascendencia, sino que es inmanente. El imperativo no es externo, antes bien es un imperativo inminente a su yo y a su circunstancia. Podemos encontrar un punto de encuentro con Heidegger, quien dirá que el ser se toma así mismo en la resolución:

En la resolución radica la estabilidad existentiva que, por su esencia, ya ha anticipado todo posible instante que de ella brote. La resolución, en cuanto destino, es la libertad para

\footnotetext{
${ }^{13}$ Ortega siente que el pensamiento kantiano hace prevalecer una razón, como hemos mencionado, a histórica. Y se refiere tanto a su teoría del conocimiento como a su formalismo ético. Una razón desenraizada de la vida. Por desenraizada entiende el filósofo español que se vuelve analítica. Por lo tanto, deja de lado la temporalidad y la finitud del hombre.
} 
renunciar a una determinada decisión si eventualmente la situación lo demandare. (Heidegger, 2009, p. 404).

Quiere decir que el hombre decide en su plena libertad por la vida o la cultura. Tengamos en cuenta que es precisamente ese punto lo que los nacionalismos toman su fuerza y desde donde se legitiman: la vida debe estar al servicio de la cultura, lo opuesto a lo que propone el filósofo español. La vida es inmanente a mí mismo: "La vida nos es dada, puesto que no nos la damos a nosotros mismos, sino que nos encontramos en ella de pronto y sin saber cómo". (Ortega, 2014c, p. 187).

Si recordamos de nueva cuenta el pensamiento de Parménides encontraremos la relación del ser con el pensamiento; aquí Ortega se distancia de aquella Metafísica y nos acerca a Heráclito, quien nos muestra la acción y el movimiento como principio ontológico. La vida es encontrarnos siempre haciendo algo. Pero no es un hacer parcial, sino un hacer con miras a decidirse a tomarse y no a huir. Las creencias nos mueven y son inmanentes nos acompañan y guardan un repertorio, las creencias en un plano social nunca son homogéneas y por lo tanto son diversas, problemáticas, confusas. Los historiadores de mentalidades han tratado de estudiar las creencias como modo de entender las vidas en una época; pienso en los grandes trabajos de historiadores como Georges Duby.

La vida para Ortega es siempre enigma, de ahí su interés por ella. Nada que ver con el pensamiento moderno, que como hemos visto, anteriormente, surge como un saber totalitario: la razón y el método. Ortega y Gasset fue un filósofo crítico de los efectos de la modernidad en las masas sociales. La creencia más engañosa es creer que hubo una época ilustrada, el propio Kant lo dice en su artículo que es un proyecto pero, ¿nosotros hemos llegado a ese momento de madurez como civilización? Tendríamos que hacer ese diagnóstico. Ahora bien, las creencias se viven y no pasan por un reconocimiento, si así ocurriera es que estamos frente a su fallecimiento. Las creencias vigentes simplemente se viven, y la sociedad del siglo XIX creyó que la ciencia había sido totalizadora y que el proyecto de la modernidad fue un hecho. 
Como podemos ver si nosotros nos servimos de la razón como instrumento, podemos encontrar de fondo una voluntad de dominio, esto lo vio muy bien el pensamiento de Nietzsche, quien fue el gran crítico de la modernidad. Ortega no se refiere tanto a la crítica del quehacer científico, sino que analiza la ciencia como creencia. La guerra civil española, la crisis del capitalismo, el auge del comunismo y la Segunda Guerra Mundial serán los acontecimientos que harán al hombre dudar de su dominio y de la idea de progreso:

No niega ni desconoce su maravilloso poder, su triunfo sobre la naturaleza; pero, al mismo tiempo, cae en la cuenta de que la naturaleza es sólo una dimensión de la vida humana, y el glorioso éxito con respecto a ella no excluye su fracaso con respecto a la totalidad de nuestra existencia. (Ortega, 2014c, p. 194).

Para ser más exactos, la crítica de Ortega se dirige a la politización de la ciencia, cómo ésta es llevada a un plano ideológico. Recordemos que científicos como Plank, el xenófobo Stark y el liberal judío Haber recibieron el Premio Nobel. Stark ayudó al régimen nazi y fue un fanático de sus doctrinas y con respecto a Haber, quien también ayudó a los nazis, y recordemos que sus propios descubrimientos fueron usados en contra de los judíos siendo él judío. ${ }^{14}$

De manera distinta ve Ortega y Gasset en Einstein, el científico no ensimismado en su trabajo o atrapado en la retórica nacionalista, sino que es el prototipo del científico comprometido con su época y con su presente, punto nodal en su pensamiento:

[...] yo pensaba que era preciso elaborar una filosofía partiendo, como de su principio formal, de excluir las calendas griegas. [...] La vida es prisa y necesita con urgencia saber a qué atenerse y es preciso hacer de esta urgencia el método de la verdad. El progresismo que colocaba la verdad en un vago mañana ha sido el opio entontecedor de la humanidad (Ortega, 2014c, p. 196).

\footnotetext{
${ }^{14}$ Haber había descubierto en 1909 un proceso para la síntesis del amoníaco a partir del nitrógeno e hidrógeno. El trabajo que lo hizo merecedor del Premio Noble fue aplicado para la creación de fertilizantes, pero en la guerra fue usado para la fabricación de explosivos. Durante la Primera Guerra Mundial trabajó en laboratorios en donde desarrolló gases venenosos.
} 
Vivir es tomar la circunstancia y cuando digo tomarla no es que se encuentre esa circunstancia fuera de mí, la circunstancia me determina y yo a ella, pero esa relación se puede mantener sin que yo haga nada. La vida nos fuerza a elegir posibilidades. Por lo tanto, el ser no puede ser una determinación, sino que este es posibilidad. La razón vital será la respuesta que Ortega tiene para hacer frente a la crisis de su tiempo. Pero la fuerza de la razón vital se encuentra en que se opone a todo razonamiento que nos lleve a suponer una naturaleza humana. Nos muestra el filósofo español su pensamiento más elevado, su antropología filosófica, donde el hombre es un ser histórico:

La vida humana, por lo visto, no es una cosa, no tiene una naturaleza, y, en consecuencia, es preciso resolverse a pensarla con categorías, con conceptos radicalmente distintos de los que nos aclaran los fenómenos de la materia. (Ortega, 2014c, p. 198).

Aquí es cuando nos lleva a pensar su idea de que el hombre tiene que resolverse, su vida es un drama y un acontecimiento que acontece a cada cual. El drama del hombre es que debe determinar lo que va a ser:

Siendo el ser de los viviente un ser siempre distinto de sí mismo-en términos de la escuela, un ser metafísicamente y no sólo físicamente móvil-, tendrá que ser pensado mediante conceptos que anulen su propia e inevitable identidad. (Ortega, 2014c, p. 200).

El concepto es algo vivo y es acción, es lo distinto a las creencias, el filósofo crea conceptos, los inventa. A las creencias simplemente nos adherimos.

\section{Por una filosofía que piense el presente}

Su libro La rebelión de las masas fue escrito en el año de 1929, el panorama y el contexto del libro es complejo por todos los acontecimientos que sucedieron en el mundo, todos ellos están conectados, cada hecho es efecto de los otros. El mundo en ese momento es un polvorín en el que 
la mecha ya se ha prendido y no hay vuelta a atrás. Ortega y Gasset habla de una hiperdemocracia que como consecuencia hace que las masas manden sobre las minorías:

He dicho, y sigo creyendo, cada día con más enérgica convicción, que la sociedad humana es aristocrática siempre, quiera o no, por su esencia misma, hasta el punto que es sociedad en la medida en que sea aristocrática, y deja de serlo en la medida en que se desaristocratice. Bien entendido que hablo de sociedad y no del Estado. (Ortega, 2014a, p. 284).

Ortega aclama una sociedad aristocrática. Antes de continuar es preciso esclarecer qué entiende por la palabra "aristocracia", remitimos a la raíz etimológica en donde aristos significa los mejores. Sabemos que tanto Platón y Aristóteles asumían que era el mejor modelo de gobernar: areté (virtud). El hombre medio, como él lo llama, es el hombre genérico que se repite y se mimetiza en la masa. No tiene esa fuerza vital que lo lleve a diferenciarse. El hombre medio no está a la altura de su tiempo, es un hombre carente de compromiso. Ortega pone de manifiesto la altitud vital, hay hombres que viven en este que es su presente, pero lo descalifican oponiéndose siempre a una nostalgia por un pasado. O puede que haya hombres que vivan en su presente y piensen en tiempos venideros; este pensamiento no es otra cosa que el nacionalismo y el comunismo.

Para el filósofo español el siglo XIX fue una época de la comodidad, de la creencia en un hombre que podía ver el tiempo hacia atrás con pedantería. Esa circunstancia era la crisis y no se le vio, por ejemplo:

Ya el nombre es inquietante: ique un tiempo se llame a sí mismo moderno, es decir, último, definitivo, frente al cual todos los demás son puros pretéritos, modestas preparaciones y aspiraciones hacia él! iSaetas sin brío que fallan al blanco! (Ortega, 2014a, p. 292).

Ortega nos sitúa en la necesidad de pensar el presente, en una filosofía que cree conceptos, que dé cuenta que no se puede pensar la crisis con el pasado; esto Nietzsche ya lo había visto, por eso la meta de su filosofía era superar la metafísica clásica. De ahí el nombre de uno de sus libros El ocaso 
de los ídolos. El ocaso de la razón occidental y con ella todas sus máscaras. Es curioso que a la destrucción le haya dado una significación festiva. Pero es claro que entre Nietzsche y Ortega hay diferencias notorias, pues el vitalismo de uno no es el del otro:

[...] hoy quiero anticipar la más obvia: proviene de que, fieles a una ideología, en mi opinión predilecta, miran de la historia sólo la política o la cultura, y no advierten que todo es la superficie de la historia: que la realidad histórica es, antes que eso y más hondo que eso, un puro afán de vivir, una potencia parecida a las cósmicas; no la misma, por tanto, no natural, pero sí hermana de la que inquieta el mar, fecundiza a la fiera, pone flor en el árbol, hace temblar a la estrella. (Ortega, 2014a, p. 293).

Decadencia es cuando se quiere huir de la vida (presente), cuando se prefiere, como mencionamos antes, el pasado o el porvenir. Mao Tse-Tung nos muestra un claro ejemplo:

En oposición a la concepción metafísica del mundo, la concepción dialéctica materialista del mundo sostiene que, a fin de comprender el desarrollo de una cosa, debemos estudiarla por dentro y en sus relaciones con otras cosas. (Tse-Tung, 1975, pp. 40-41).

¿Qué significará esto en la práctica y en su aplicación histórica? Mao analiza la historia de manera abstracta, sabemos que la revolución China se dio en un contexto del que Marx jamás contempló, un país agricultor y no industrializado. La contradicción, en todo caso, se manifiesta entre los terratenientes y los agricultores, pero no con los capitalistas. A final de cuentas, los acontecimientos históricos se pueden ajustar al sistema. ${ }^{15}$

En los aparatos ideológicos la vida se reduce a nada, queda olvidada y se le menosprecia por otros valores. La historia se convierte también en un instrumento de la cultura y se tiende a falsificar todo, la historia y las personas:

Este espíritu de sacrificio, dispuesto a arriesgar el trabajo personal y si es necesaria la propia vida en servicio de los demás, está indudablemente más desarrollado en el elemento de la raza aria que en el de cualquier otra. (Hitler, 2000, p. 103).

\footnotetext{
${ }^{15}$ Puede seguir explicándolo desde la contradicción.
} 
¿Qué modelo de gobernar es el que estima Ortega y Gasset? Pensó que la democracia liberal representaba la forma más acabada en la que el hombre podía ser libre. Aunque siempre pensó que el liberalismo no estaba acabado y que sería necesario contribuir a su mejora:

La forma que en política ha representado la más alta voluntad de convivencia es la democracia liberal. Ella lleva al extremo la resolución de contar con el prójimo y es prototipo de la acción indirecta. [...] se limita a sí mismo y procura, aún a su costa, dejar hueco en el Estado que él impera para que puedan vivir los que ni piensan ni sienten como él, es decir, como los más fuertes, como la mayoría. (Ortega, 2014a, p. 324).

Ortega no piensa en un liberalismo cuantitativo de las mayorías, sino en un modelo de tipo cualitativo, en el que los que ofrecen mejores argumentos son los que deban tomarse en cuenta. La filósofa alemana Hannah Arendt tenía un pensamiento muy parecido con respecto a este punto con el filósofo español. La fuerza de una auténtica política reside en iConvivir con el enemigo! ¡Gobernar con la oposición! Por lo tanto, la crisis de su tiempo fue tomar partido por el fascismo o el comunismo. Pronto verá ese drama en España y nunca se podrá reponer de lo acontecido, la división social y la barbarie se hizo algo cotidiano, se preguntará: ¿en dónde habrá quedado el valor de la vida?:

Los que antes del 18 de julio eran simplemente adversarios políticos se convierten en enemigos de la noche a la mañana. [...] Azaña: el odio destilado lentamente durante años en el corazón de los desposeídos; del otro, el odio de los soberbios, poco dispuestos a soportar la insolencia de los humildes. [...] José Luis de Vilallonga: “Todavía recuerdo el día en que, un poco antes de la guerra, mi abuela dijo de pronto: Siento un infinito desprecio hacia los pobres. Y como todo el mundo se quedó con la boca abierta, explicó: Sí, porque ¿cuántos son ellos? Millones. Y los ricos ¿cuántos somos? Muy pocos. Pero aquí estamos desde hace siglos sin que a nadie se le ocurra hacernos nada". [...] El mismo 18 de julio, los milicianos asaltan el hospital Gómez Ullua, secuestran al general López Ochoa, que convalece de una operación, lo fusilan, castran al cadáver, lo desorejan, lo decapitan 
y pasean por las calles de Madrid la cabeza ensartada en el palo de una escoba. [...] El mismo día, en la Coruña, los rebeldes detienen al joven gobernador Francisco Pérez Carballo y a su mujer, Juana Capdevilla. A él lo fusilan. Ella sufre un aborto en la cárcel. A los pocos días de liberarla, unos derechistas la detienen de nuevo, la violan y la asesinan. [...] Otro caso similar es el de Muñoz Seca, celebrado dramaturgo, autor de La venganza de don Mendo. Lo detienen el primero de agosto y lo ingresan en el departamento 2 de la planta baja de la cárcel. Frecuentemente visita la cárcel el escritor izquierdista Pedro Luis de Gálvez, al que Muñoz Seca había abierto algunas puertas en el difícil mundo de las letras. --"A éste que nadie me lo toque"-advierte a los carceleros señalando a Muñoz Seca一, "que a éste lo quiero matar yo personalmente, ¿iverdad, maestro?" [...] A Julián Marías lo acompañó toda su vida un recuerdo lacerante: Íbamos en el tranvía, torcíamos desde Alcalá para entrar en Velázquez, y una mujer que iba sentada en la fila de adelante señaló con el dedo hacia una casa, un piso alto, y le dijo a otra con la que viajaba: "Mira, ahí vivían unos ricos que nos los llevamos a todos y les dimos el paseo. Yo a un crío pequeño que tenían lo saqué de la cuna, lo agarré por los pies, di unas cuentas vueltas y lo estampé allí mismo contra la pared. Ni uno dejamos. A la mierda la familia entera". (Eslava, 2016, p. 80).

\section{Conclusión}

La guerra civil española dejó un profundo vacío en la España de Ortega. Quizás ese vacío se fue construyendo años antes a la guerra: el paso de la primera República, la dictadura de Primo de Rivera y posteriormente la segunda República, para finalizar con la Guerra Civil y la dictadura de Franco. Todos estos momentos históricos nos muestran lo convulsionada que estaba la vida en aquel país. Tomando en cuenta también todos los sucesos que no fueron menores y que ocurrían fuera de las fronteras de España, no podemos sino entrever que tarde o temprano se llegarán a tocar para después colapsar. El punto de encuentro se dio en la guerra civil española, que fue preámbulo de la Segunda Guerra Mundial. Este conflicto bélico se originó por el choque de ideologías, que como sabemos, penetran en todos los estratos sociales e intelectuales y se diseminan en el hombre medio (masa). A diferencia de la Primera Guerra Mundial que surgió por el 
choque de los imperialismos. Es de subrayar que por momentos Ortega y Gasset se refiera al español en términos de docilidad. A lo mejor y sea la "docilidad" un efecto de las ideologías que crean pensamientos y comportamientos homogéneos. Por eso no nos sorprende que el filósofo español inicie en la Rebelión de las masas con un diagnóstico de su tiempo. Lo que nos muestra que Ortega y Gasset estaba conectado con su tiempo, que dialogaba con sus contemporáneos y que en varios momentos instaba tanto a los pensadores de su tiempo como a él mismo a la urgencia por definirse y de no ser apolítico. Habría que seguir pensando si su silencio se convirtió en una forma de continuar hablando o si su silencio fue una forma de abandonar la palabra; esto en cierta forma sería lo más trágico para un pensador que siempre invitó a pronunciarse. También podemos entrever que la invitación a definirse políticamente tiene dos caras: una filosófica y otra política, pues en Ortega coexistían esos dos momentos. Nuestro filósofo veía la política y la filosofía como ejercicios, desde la óptica de la acción. Ortega siempre se definió como un liberal ya que veía a esta doctrina como una práctica discursiva y la cual ponía en su centro la posibilidad de disentir. ${ }^{16}$ Ideas y acción se necesitan ambas; un partido o un movimiento que no tenga ideas no podría tener buen puerto su naufragio sería inminente. La vida de España y la de Europa era un recorrido hasta ese entonces sin proyecto, y sin éste no podría haber porvenir, a caso un proyecto puede ser un volver a un pasado o la promesa de un futuro. Pero cualquier movimiento si se lleva a cabo desde la docilidad se avecinará el desastre.

El raciovitalismo y su concepción de la historia se fundirán, para que Ortega pueda decirnos algo con respecto a su presente y hablar así a sus contemporáneos. Ambos conceptos lo llevan a poner en el centro la vida y no la cultura. Dice Ortega: vivir es tratar con el mundo. Esto nos lleva a pensar la vida como actuar, proceder de una cierta manera. Hay dos maneras de oponerse a la vida: la primera es la docilidad, la segunda es la violencia. La razón para Ortega no es solamente opinar, sino que es ante todo querer la verdad. La razón es entonces una actividad que nos tiene que conectar con nuestra circunstancia. Por lo tanto, rechazará toda racionalidad trascendental o

\footnotetext{
${ }^{16}$ Sabemos que Ortega estaba en contra de la profesionalización de la política.
} 
racionalidad que no se piense dentro de un marco histórico. ${ }^{17}$ Cuando se habla aquí de realidad, esta no proviene de lo que uno quiere, es por eso que usa la palabra topar, no la topamos queramos o no. La relación entre razón y realidad conlleva una tensión de origen. Las ideas tienen que surgir de esa tensión, surgen de la crítica, de la relación entre individuo y el hecho histórico en el que él mismo se encuentra inmerso; es por eso que no podemos si no pensar en una inestabilidad continua. Y este punto será crucial para entender que la idea es imaginación, pero que no evade la circunstancia, sino que permite tomar la circunstancia y buscar cambiarla. No habría un concepto que más odie la filosofía de Ortega en el que se afirmara que el hombre es un mero adaptarse a su circunstancia. Por lo tanto, en su concepto de raciovitalismo podemos encontrar dos filosofías que lo acompañaron en su trayecto: Emmanuel Kant y Nietzsche.

Sin embargo, el concepto fundamental para entender su aportación es el de historia. Es indudable que la lectura de Dilthey fue importante para tomar distancia del positivismo y de la lectura de Hegel de la historia. La historia surge de la actividad humana y es importante adentrarse en la vida cotidiana para entender la vida de las personas. Entender cómo un sistema de pensamiento surge es a su vez entender los detalles, los gestos, lo que hacía x persona, sus relaciones con los otros, lo que lo rodeaba en ese momento, los sucesos históricos de los que era parte. No solamente como un espectador sino que agente. El concepto de vida en Dilthey será también relevante en Ortega y Gasset; pues nuestra vida no se limita a un mero representar el mundo, sino que cambiamos en el movimiento mismo de la historia nuestro estado de ánimo y las formas en las que hacemos las cosas. A esto se refería Ortega cuando hablaba del impulso vital de una época. Conocer por tanto el impulso vital de una época es conocer ante todo sus valores y los fines que se han impuesto. Es penetrar en sus ideas, los sentimientos que los movían, sus vivencias, etc. El hombre no es por tanto una cosa sino que es un acontecimiento, que cada uno tiene que desentrañar y que se resuelve eligiendo entre sus posibilidades aquella que le es auténtica. Es por

\footnotetext{
${ }^{17}$ Habría que analizar el concepto de memoria histórica, ya que este término nos lleva en muchas ocasiones a petrificar la memoria, quitándole el dinamismo que la palabra misma nos lleva a pensar. De ahí que pueda darse un tipo de resistencia para distinguir entre memoria e historia.
} 
eso que no hay otra forma de entender su filosofía que no sea desde un doble plano: la persona y su obra, ambas conforman una vida de grandeza y también de decadencia.

\section{Referencias}

Arendt, H. (2017). La condición humana. México: Paidós.

Eslava, J. (2016) Una historia de la Guerra Civil que no ha de gustar a nadie. México: Crítica.

Gracia, J. (2015). José Ortega y Gasset. México: Taurus

Hegel, G.W.F. (2011). Ciencia de la lógica. España: UAM

Hitler, A. (2000). Mi Lucha. México: PNSAL

Ortega, J. (2014a). La rebelión de las masas. España: Gredos.

Ortega, J. (2014b). En el centenario de Hegel. España: Gredos.

Ortega, J. (2014c). Historia como sistema. España: Gredos

Medin, T. (1994). Ortega y Gasset en la cultura hispanoamericana. México: FCE.

Marx, K. (2014). Textos de Filosofía, política y economía. España: Gredos.

Nietzsche, F. (2014). Así hablo Zaratustra. España: Gredos.

Tse-Tung, M.T. (1975). Tesis filosóficas. México: Roca. 